\title{
LEAVING THE FIELD IN THE DigITAL AGE
}

Felix Girke

\begin{abstract}
Anthropologists' arrival stories have long served to justify, naturalize, and domesticate-often through humor-the fraught moment of entering unasked into other people's lives. This textual convention has been thoroughly critiqued, but no comparable attention has been paid to the analogous moment of departure from the field. The digital age enables both sides to maintain contact, a shift that negates the finality of earlier departures. This article engages the changes wrought by digital media that allow us to remain connected to the field. While this seems a humane affordance, it also means that it is no longer feasible to cleanly sever ties established 'there'. When anthropologists leave the field, the field will likely follow them-on Facebook or Instagram.
\end{abstract}

Keywords: arrival, connectivity, departure, digital age, fieldwork, methodology, the field

In his poem "Leaving the Field," published in Antipodes, anthropologist Michael Jackson (1996: 15) evokes the anticipation, unease, and conflicted positionality of the moments just before departure:

Snatching at images

in my last hours here:

the green-black Bloomfield ridged

and ridged again, mullet

hurling themselves

from the abscessed water ...

The rain is a cape of beaten bark

over the hill's arthritic shoulder.

McGinty throws his bait net out.

Hand over hand

he draws it in,

shakes silvery bream onto the greying sand. 
The whoop and fluting of a bird;

a second bird answers.

Jackson 'snatches' at images, but he has seen it all before, many times, probably. He knows that the fish are not just fish, but mullet and bream; he has often sat and reflected on the particular shape of that hill, and on the various textures of the rain; he has talked with McGinty time and again, observing his techniques, even assisting him in his work. Jackson cannot identify the bird: his knowledge, while exhaustive (exhausting?), is partial still. Even if he was not departing and could continue observing and participating, there will always be that second bird that he will not know. Departure is inevitable; stalling and postponing it, while understandable, will not change the relation of the anthropologist to the field. And McGinty will continue fishing after Jackson has gone. Does McGinty care that Jackson is leaving?

This poem can cast readers back to their own final days of fieldwork. How were your departures? What did you snatch at? What did you take, what did you leave behind? What did you write in your field diary, on the very last page? Did your departure make it into one of your publications? What is your relation to the field now? Which relations did you sever, which do you still maintain, if any? Did you somehow mark the passage from (sacred?) field to (profane?) home? But beyond possibly ephemeral memories lurks the question of training and method. Were you trained for leaving the field? Was this even discussed in preparatory meetings?

Contemplating departure from the field as a personal experience is usefully complemented by methodological considerations and more literary reflections. The necessary reconfiguration of 'departure' under conditions of social media in the digital age-when physical absence can be compensated for in various ways - changes our very understanding of 'the field'.

\section{From Arrival to Departure}

This article takes its cue in part from Clifford and Marcus's collection Writing Culture. In “Fieldwork in Common Places," Mary Louise Pratt (1986) taught us to read opening sections of ethnographies as complex assemblages. These passages not only introduce us to the ethnographers, but also outline the respective conditions for conducting research, emphasizing shared humanity while already hinting at the dissimilarities that will make a difference. They often anchor the account to a particular historical moment, or a genre of regionalist travel writing. Yet regarding the departure from the field, we find not just fewer carefully curated accounts, but much less material in general. However, as the British sociologist Nick Fox (2008: 483) notes in his contribution to the SAGE 
Encyclopedia of Qualitative Research Methods, "self-presentation, negotiation of roles, research bargains and interactions, and personal relationships with informants and other participants" surely are as important when leaving the field as when entering it.

Field research usually ends-especially for younger scholars-when an externally determined time period is up: we go into the field for a number of months, and then return to our institutions. Not all go abroad for entire years; few even have the opportunity to do so, as many (by intention or necessity) conduct multi-sited projects and weave multiple shorter stays in the field into their academic workload. Researchers might also want to leave for reasons that have little to do with the field and more to do with their connections and commitments elsewhere. But even if departure feels not like something we actively do (since few can freely decide upon the end of their physical stay), the discursive void around leaving the field is noticeable. Few textbooks and ethnographies address the topic, as if in avoidance behavior. Sara Delamont (2016: 4) speaks of "the academic neglect of exits." In his book Doing Ethnography, Giampietro Gobo (2008: 306) finds it suspicious even: "It is probably due to the predatory mentality still prevalent among ethnographers and social researchers in general. They pay close attention to how to collect the data, but once they have filled their bags, they escape with the loot, never to be seen again."

This is an uncharitable interpretation to launch against anthropology at large, but for me, the accusatory tone struck a note; I myself had employed this notion, in reverse, as leverage to ingratiate myself somewhere at the expense of somebody else. During my first or second stay in the field in southern Ethiopia, I inquired about a researcher who had worked in the region for his MA 10 years earlier. "Has he ever come back?" I asked. "No," my interlocutors affirmed, "no, he has not." I let the subsequent silence stand for too long-I, of course, would always be coming back. Utilizing the privileges of my relatively wellendowed research grant and institutional support, I tried to plant the idea that I was not just a more serious researcher, but also a better person. My fieldwork idol at the time was Ivo Strecker, who had begun research in a neighboring region in the late 1960s and 40 years later was returning regularly-and still visits today at the age of 80 . At the time, I viewed this as the epitome of an anthropological life: to never really leave.

\section{Leaving the Field as a Personal Experience}

But even as one visit will (maybe only in retrospect) turn out to have been the last one in physical terms, the notion of departure has metaphysical qualities. "Did I ever leave the field?" asks Jeffrey van den Scott (2018: 304), and this question goes to the heart of the matter. Similarly, Delamont (2016: 8) observes: 
"Overall, it might sound pretentious, but it is accurate to say, that because of writing about, and therefore thinking about, the [two specific field sites] for many years after the physical fieldwork in some ways I never did 'leave' those fieldsites in my head, though I have not been physically present in them for many years." Leaving, for her-that is, the physical departure and the termination of her participation in the group events she was studying-meant "terminating a big part of my identity" (ibid.: 13), including a name that she had gotten used to. Clearly, even from merely a personal perspective, "leaving the field-if we ever truly do-is a process more complex than simply physically moving from one location to another" (van den Scott 2018: 309). It is "one of the most delicate aspects of ethnography," as Gobo puts it (2008: 131), which should not be treated as an "automatic procedure" (ibid.: 105) but engaged in with care and reflection. ${ }^{1}$

Fieldwork transforms the researcher, and often enough their research partners, who, as van den Scott (2018: 305) recalls, become the "friends and participants who played such a vital role in my early career and life." The point that many early career ethnographers are young and in formative stages of their lives, with precarious ties to home, careers, and visions of their future, matters. Because of personal entanglements or the very tangible transformation of our identities, we notice that we have become who we feel we are partly due to fieldwork. Even if relations are more utilitarian, as when we strike "research bargains" (Fox 2008: 483) in which the quid pro quo of reciprocity is clear to all involved, identities are becoming entangled.

Fox (2008: 483) speaks of "ethical dimensions" regarding departure in general, and possible "ramifications for participants after the researcher has left the field." ${ }^{2}$ To ground this vague precept in radical example, consider the cases of the aforementioned Ivo Strecker and the Swiss anthropologist Conradin Perner, who (coincidentally?) both worked among agro-pastoralists of the EthiopianSudanese borderland from the 1970s onward. Each has articulated their friends' and interlocutors' reactions toward the ethnographer's departure. Perner (2017) titled his retrospective on fieldwork among the Anyuak Why Did You Come If You Leave Again?-a question asked to his face by a local elder who saw him packing for an intermediary return to Switzerland. When Perner reassured him that he would be back soon, the elder replied sadly that "good people never come back." Similarly, Strecker (cited in Girke 2018: 26) recalls:

When I gave my inaugural lecture at the University of Mainz, it was about [field] research and friendship. And there, I narrated how-after, then, years of coming and going there-I had told the Hamar 'now it's enough! I am fed up with your way of life and all that stuff ...' There had been a crisis, when the tribal feuds had become too intensive again, and I could not bear it, and then the Hamar said, 'no, friendship is forever, and you can't just come and say 'I want to be your friend' and then say 'now the friendship is over'! 
These two, having worked in face-to-face societies well before any mediated post-fieldwork communication was feasible, came up against local models of relationships that entangle the less than transient visitor, namely, you do not get to say when it is over-a variation on Fox's (2008: 483) "culturally appropriate forms of valediction." Over the years of my research among the Kara, the western neighbors of the Hamar, whenever I did return-which I do much less frequently today-I was regularly confronted with the provocative prompt, "Ya kalun kayidu?!" fairly translated as, "And you, did you totally perish in the meantime?"

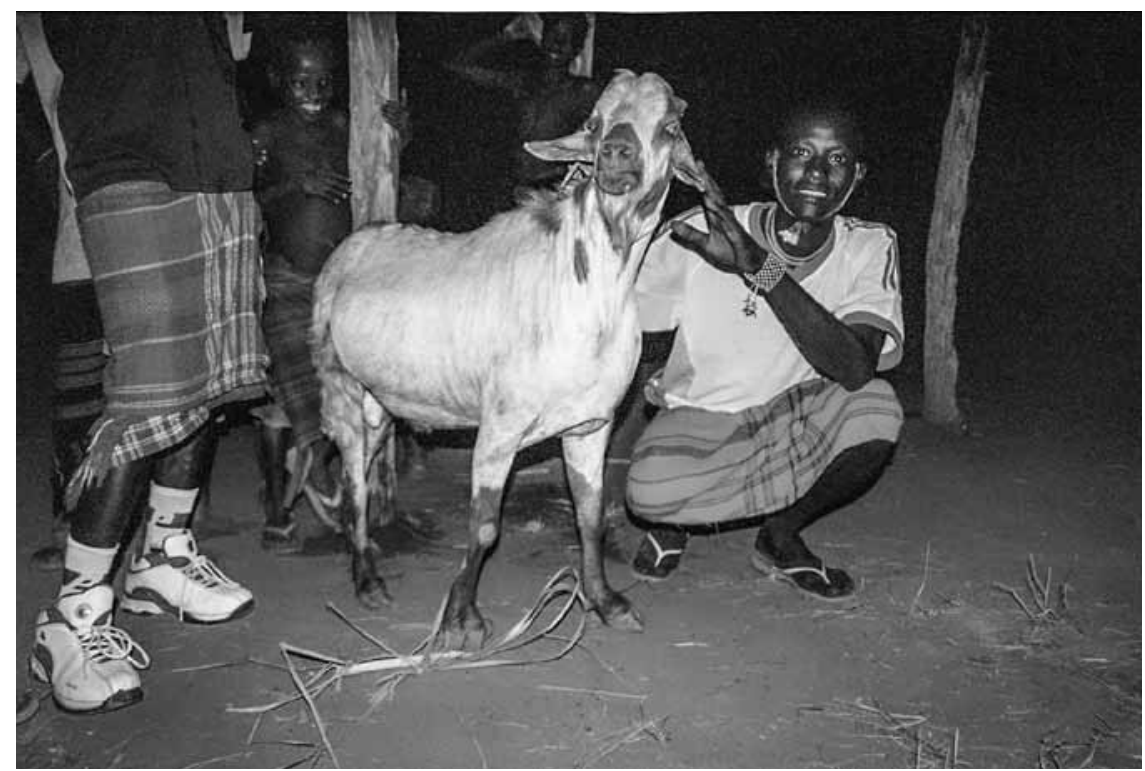

FiguRE 1: A goat to be slaughtered on the occasion of the author's departure from Kara (Ethiopia) after one year of fieldwork, chosen for its massive size. February 2007. Photograph $\odot$ Felix Girke

\section{Leaving the Field as a Methodological Consideration}

As we do have to leave our fields eventually, it would seem warranted to make the most of it in terms of methodology, even if-say, as graduate students being summoned home-our agency and decision-making capability to influence the fact of physical departure are much constrained. In his book Doing Ethnography, Gobo (2008: 306) seeks to operationalize and professionalize the process by articulating five "Learning Objectives" for his target audience of graduate students: 
- To understand when it is time to leave.

- To grasp the importance of devising an efficacious field exit strategy.

- To know the main difficulties in disengagement.

- To learn how to take one's leave of participants.

- To gain knowledge of ways to keep in touch.

While I accomplished these goals with some degree of success, I was little prepared ahead of time, and surely did not make the most of them. I now agree with Delamont (2016: 17), who suggested that “just as access negotiations and first encounters are extremely revealing about the subculture(s) under study, so too the exit processes may be just as academically productive." The literature on methods does suggest some ideas for when one departs for genuinely researchbased reasons, such as “'diminishing analytic returns'. That is clearly the best reason for leaving a field site, and one that should be written about, thoughtfully, more than it has been" (Delamont 2016: 6, citing Gary Fine). Already in their Discovery of Grounded Theory, Barney Glaser and Anselm Strauss (1967) had introduced 'theoretical saturation' as an objective, after which departure was warranted. Gobo (2008: 312) summarizes other parameters-such as reaching "taken-for-grantedness" of events ${ }^{3}$ and "heightened confidence" in interpreting the collected material-as indicators that leaving the field is justified. Gobo also warns of the "compulsive scientism" addressed in Grounded Theory, that is, the tendency to "collect much more data than [one is] able to analyze" (ibid.).

To point to the possibly compulsive aspects of data gathering emphasizes how a self can come to depend on the academic project: any firm division of personal and methodological considerations will miss the mark. Much rather, we must extend the inquiry into staying in touch to include questions of data gathering. If we do keep open lines of communication with interlocutors from our field, beyond ethical and personal reasons, we are also keeping a back door open for gathering more data, even from afar. There are other considerations somewhere between the personal and methodological, such as "issues of power, gender and age” (Delamont 2016: 4), and the curious calls for "strategies to withdraw with professional dignity and honor" (Gobo 2008: 308) or 'graceful' departures. The modalities of these, too, will depend on local conditions and the interpersonal skills of the fieldworker, and would hypothetically lend themselves well to literary presentation.

It would require a dedicated (and separate) effort to trawl ethnographies and tease out what scholars have in fact written about leaving the field, and where they place descriptions of or reflections on this very significant moment. Delamont (2016: 5) finds that "the autobiographical or 'confessional' literature is ... thin on autobiographical leaving stories.” If Jeffrey van den Scott's (2018: 306) observation-that "one of the key indicators I found of my readiness to leave is a dramatic reduction in the quantity and quality of my field notes" (see 
also Delamont 2016: 17) —is even half representative, then it is understandable that a departure will leave fewer traces in people's writings.

But in contemporary ethnographies, we might well find even less of this. In stark contrast to the 1970s examples of Strecker and Perner referenced above, consider Anne Beaulieu's (2010: 454) fine Goffmanian distinction between 'colocation' and 'co-presence', as applied to her laboratory studies: "While physical co-location can be a resource for participants, it is not in itself a sufficient criterion for co-presence. Co-presence decentralizes the notion of space without excluding it. It opens up the possibility that co-presence might be established through a variety of modes, physical co-location being one among others." For the Anyuak and the Hamar, this clearly was not the case: co-location was the necessary requirement for co-presence, and the researcher's departure meant an end to an episode of their lives.

\section{Reconfiguring 'the Field' in the Face of Connectivity}

Digital media allows us to remain connected to the field indefinitely, without much logistical effort and with negligible costs. This seems, at first, a humane affordance regarding the social relationships we have developed and the personal transformation we might have undergone: we do not need to give it all up; we do not have to return home entirely; we can keep our feet planted in both places. Mutuality and reciprocity are neither concluded nor shifted to the realm of nostalgic memory; instead, commitments remain active as we prefer, and as we hope our interlocutors do as well. Unlike those who came before, we are enabled by technology to never really leave the field, and our research partners, likewise, can always connect to us. Beyond upholding communication for the sake of relations, we remain connected to the field in that we can continue to update data from the modern armchair, our comfortable 'Internest' on the couch.

But this seeming advantage has its barbs. It is no longer feasible to cleanly sever those ties established 'there' as it had been for our predecessors, even if desired, by one side or both. When anthropologists physically leave the field, the field will likely follow them-on Facebook and Instagram. And even if those we have written about do not 'write back', and maybe do not even read what we write, they are out there, a mouse click away, constant reminders of a time spent physically in a field. We should at least consider the possibility that leaving the field for good and concluding relations and going on with our own lives while letting other people go on with theirs might have had its benefits. I, personally, suffered helplessly from afar when receiving bad news from my field in southern Ethiopia after returning to Germany from long-term fieldwork. Deaths, disasters, diseases-I could have coped better had these occurred when I was physically present. Learning about them from a distance, I felt vulnerable 
and isolated, and no phone call or video chat would have compensated. I did not wish to sever the ties that bound me to the field then, and I still do not, but I quite understand if somebody else would have wanted to do so.

Van den Scott (2018: 304) correctly states that today the field "can be physical, social, cultural, virtual, mental, or any combination of these features," so arguably, any separation between 'field' and 'not field' is becoming less and less tenable. Entering the field still seems a transformative moment, even if we now have ways to establish contacts elsewhere long before we hop on the plane, and usually no longer need weeks to get to a remote village or island. But leaving the field has irrevocably changed, and not just in disavowing a "clear end-point" and instead seeing the "research journey" as consisting of "different stages of reflection" (Fay 2015). The connectivity in our relation to the field has changed-we are now forevermore betwixt and between, entangled with another place and other people. Because of unconstrained connectivity, 'being there' (Watson 1999) is not the same as it was, nor is 'being here'. When physically leaving the field, we mark a transition by actively (if half-heartedly or haphazardly) cordoning off that part of a life, consigned to the place that we leave, something that the leaving fieldworker of Jackson's poem is only slowly coming to terms with. That old rite de passage, when we allow(ed) anti-structure to overwhelm us, is still somehow sacred; we not only leave, but also return to enter a new phase of our lives. But we can no longer step on the steamer and only look forward: today, indeed, co-location is no longer necessary for co-presence. Thus, while it is overdue to address departure in our methods classes and to actively engage with how to leave during fieldwork (and to reflect on this in our writing), this insight must already be adapted to our new indefinite normality of inevitably still being there by way of digital connectivity, with all its methodological, political, and affective ramifications.

\section{Acknowledgments}

I thank Anna-Maria Walter and Geoffrey Hughes for feedback and for organizing the occasion for putting together my long-congealing thoughts on leaving the field in the first place, Eva Theunissen for her thoughtful commentary, and Judith Beyer for cuts. 
Felix Girke is a social-cultural anthropologist who has done extensive field research in both Myanmar and southwestern Ethiopia. He has edited four volumes and is the author of The Wheel of Autonomy: Rhetoric and Ethnicity in the Omo Valley (2018). A monograph about the constitution of political subjects through heritageization in Myanmar is in preparation. He is a series editor of Berghahn's "Studies in Rhetoric and Culture" and a member of the editorial collective of Allegra Lab. His current research focuses on the nexus of immobility and intangible heritage in the Lake Constance area. E-mail: felix.girke@ htwg-konstanz.de

\section{Notes}

1. Gobo (2008) also reminds his readers of the obligation they have to the discipline and those who come after them-namely, not to burn bridges in a place where other researchers might arrive at a later time.

2. Many ways exist to seek compensation for the asymmetry engendered by a fieldworker's departure, and not all of them successfully reconcile ethnographers' plans with their partners' expectations. Some researchers, myself among them, receive mandates as they leave, such as to tell about a group's worries and troubles back home, in the hope that someone, somewhere, can effect a change for the better.

3. Here Gobo is referencing Snow (1980).

\section{References}

Beaulieu, Anne. 2010. "Research Note: From Co-location to Co-presence: Shifts in the Use of Ethnography for the Study of Knowledge.” Social Studies of Science 40 (3): 453-470.

Delamont, Sara. 2016. "Time to Kill the Witch? Reflections on Power Relationships When Leaving the Field." Gender Identity and Research Relationships 14: 3-20.

Fay, Franziska. 2015. “Life after \#Fieldwork: Of Leaving the Field, Entering Liminality and Relocating the Mind \#Fieldnotes.” Allegra Lab, 15 September. https://allegralaboratory.net/life-after-fieldwork-of-leaving-the-fieldentering-liminality-and-relocating-the-mind-fieldnotes/.

Fox, Nick J. 2008. "Leaving the Field.” In The SAGE Encyclopedia of Qualitative Research Methods, Vol. 1, ed. Lisa M. Given, 483-484. Thousand Oaks, CA: Sage. 
Girke, Felix. 2018. "A Homage to an Anthropologist, a Homage to Anthropology, and Anthropology as Homage to Cultural Ingenuity." In Anthropology as Homage: Festschrift for Ivo Strecker, ed. Felix Girke, Sophia Thubauville, and Wolbert G. C. Smidt, 19-28. Cologne: Rüdiger Köppe.

Glaser, Barney G., and Anselm L. Strauss. 1967. The Discovery of Grounded Theory: Strategies for Qualitative Research. Chicago: Aldine.

Gobo, Giampietro. 2008. "Leaving the Field." In Doing Ethnography, trans. Adrian Belton, 306-313. Thousand Oaks, CA: Sage.

Jackson, Michael. 1996. Antipodes. Auckland: Auckland University Press.

Perner, Conradin. 2017. Why Did You Come If You Leave Again? The Narrative of an Ethnographer's Footprints among the Anyuak in South Sudan. Kindle ed. Bloomington, IN: Xlibris.

Pratt, Mary Louise. 1986. "Fieldwork in Common Places." In Writing Culture: The Poetics and Politics of Ethnography, ed. James Clifford and George E. Marcus, 27-50. Berkeley: University of California Press.

Snow, David A. 1980. "The Disengagement Process: A Neglected Problem in Participant Observation Research.” Qualitative Sociology 3 (2): 100-122. van den Scott, Jeffrey. 2018. "Leaving the Field/Can You Leave the Field?" In The Craft of Qualitative Research: A Handbook, ed. Steven W. Kleinknecht, Lisa-Jo K. van den Scott, and Carrie B. Sanders, 304-310. Toronto: Canadian Scholars' Press.

Watson, C. W., ed. 1999. Being There: Fieldwork in Anthropology. London: Pluto Press. 